\title{
Search Project Report; Field Study on Farm Workers Occupational Health Hazards Associated with Camels Zoonotic Dermatophytosis, with Reference to Fungal Etiology, and Morbidity Rates, Taif, KSA
}

\author{
${ }^{*}$ Sherifa Mostafa M. Sabra and ${ }^{2}$ Mohamed Salem A. Al-Harbi \\ ${ }^{* 1}$ (Corresponding author, Microbiology Branch, Biology Department / Animal Health Research Institute \\ [AHRI], Dokki, Giza, Egypt) \\ ${ }^{2}$ (Chairman of Biology Department, Zoology Specialty) \\ ${ }^{*}{ }^{\& 2}$ (Science college, Taif University, KSA)
}

\begin{abstract}
This investigation paper was discharged from the search project (No. 1-435-3065), with the same title, which was under the coast of Taif University, KSA. The work steps were done at Taif area, KSA, it was studied on 15farms, 1187camels and 45(farm workers) farmers. The farmers were 42.2, 31.1 and 26.7\% with nationality Somalis, Sudanese and others. Camels were infected by superficial skin mycosis 19.2, also farmers were $24.4 \%$ infected by zoonotic superficial skin mycosis. The 11 farmers infected had given 37 specimens from their lesions area, which resulted 29.7, 18.9, 18.9, 16.2 and 16.2\% from upper limbs, lower limbs, body, heads and faces of them. Results of Dermatophytes isolation and identification were 34.4, 26.6, 17.2, 12.5 and 9.4\% from upper limbs included spp. (T. unguium and T. manuum), lower limbs (T. unguium, T. pedis, Tri. verrucosum and Tri. rubrum), body (T. corporis, T. cruris, Tri. verrucosum and Tri. rubrum), faces (T. barbae and T. faciei) and heads (T. capitis). Results were 92.2 and $7.8 \%$ of T. and Tri. The results of Tinea spp. were 28.1, 17.2, 10.9, 10.9, 9.4, 7.8, 4.7 and 3.1\% for T. unguium, T. manuum, T. pedis, T. corporis, T. capitis, T. barbae, and T. cruris, while Trichophyton spp. were 4.7 and $3.1 \%$ for Tri. verrucosum and Tri. rubrum respectively.
\end{abstract}

Keywords: Farm workers, Farmers, Superficial skin mycosis, Zoonotic, Dermatophytes.

Symbols: No.: Number, Spp.: Species, T.: Tinea, Tri.: Trichophyton.

\section{Introduction}

Dermatophytosis are mycoses (fungal infections) of skin caused by Dermatophytes filamentous fungi which have the ability to invade the epidermis and keratinized structures derived from it such as hair or nails. They comprise three genera: Trichophyton (Tri.), Epidermophyton and Microsporum, related to microorganisms (MOs) in the soil which are capable of digesting keratinous material ${ }^{[1]}$. Fungal infections caused by Dermatophytes are limited to the superficial layers of epidermis and keratin-consisting skin appendages such as nails and hair ${ }^{[2]}$. Based on the source of the infection, Dermatophytes can be divided into three groups: anthropophilic, zoophilic and geophilic. Tri. rubrum belongs to the anthropophilic group meaning that it spreads mostly among humans and very rarely affects animals ${ }^{[3]}$. A survey of Ringworm $(R W)$ in camels showed over $25 \%$ of young animals suffered from Tri. verrucosum infection $11 \%^{[4]}$. Camels less than 3yrs. age and is characterized by circumscribed crusty hairless lesion, $1-2 \mathrm{~cm}$ in diameter distributed over the head, neck, shoulder, limbs and flanks ${ }^{[5]}$. Skin scrapings 136 from camels suspected had given 77/136 Tri. verrucosum. Both female and male camels were susceptible and camels less than 3 yrs. old were more susceptible to infection ${ }^{[6]}$. Higher prevalence of $R W$ due to Tri. spp. infection in Bactrian than in Dromedary camel and a higher prevalence in the she camel $77 \%$ than males $23 \%$, which included Tri. verrucosum, and Tri. rubrum. which caused sporadic cases of skin infections in individually maintained camels as well as affecting many camels in the herds. These fungi create distinctive lesions of $R W$ observed with Tri. spp. were comparatively dry, hard, crusty, granulomatous and larger in size ${ }^{[7]} . R W$ is zoonotic disease and highly contagious, as well of animals are scanty and rarely reported. Zoophilic Dermatophytosis are sporadic infections of man caused by Dermatophytes typically invading animals. many improvements are needed in the field of occupational medicine in farming ${ }^{[8]}$. Persistent Dermatomycosis $(R W)$ caused by Tri. verrucosum affected 20dairy calves spread to 2animal attendants working among the calves. Two animal attendants developed skin lesions that were circumscribed and itchy ${ }^{[9]}$. Fungal infections of the skin are especially typical of agricultural workers. Each day, farmers spend several hrs. in rubber boots which provide an ideal microclimate for the development of fungal feet infections ${ }^{[10]}$. In 1997 skin diseases formed $10.8 \%$ of all newly acknowledged occupational diseases in farmers in Poland, while the respective figures for 1995 and 1996 were $11.2 \%$ and $13.4 \%$. According to German 
statistics, in 1994 a total of 559 farmers with skin problems had been subjected to medical evaluation because of possible occupational dermatitis. In the same year, 37occupational skin diseases in farmers were acknowledged and compensated which comprised $12.9 \%$ of all occupational diseases in farmers ${ }^{[11]}$. There is no compulsory medical assessment before one starts work as a farmer. Many patients meet an occupational health professional for the first time when the disease is already advanced and legal action towards obtaining an occupational rent has already been issued. In these circumstances, confirming or rejecting the possible occupational etiology of a given dermatomes is very difficult ${ }^{[12]}$. The frequency of zoophilic fungal infections among farmers compared to non-farmers in eastern Poland, was carried out on adult patients with a suspicion of fungal infection of skin or its appendages. Dermatophytes infection was found in farmers $55.2 \%$. whereas zoophilic dermatophytes in farmers $4.3 \%$. Tri. verrucosum was found in 3cases. Zoophilic fungi were responsible either for superficial mycosis ${ }^{[13]}$. Animals can infect humans with Dermatophytes, occupational relationship is established when the same fungus is isolated from both the animal and worker, 995cases of zoophilic dermatophytosis were registered as occupational dermatomes in the farmer German Democratic Republic over a 4yrs. period ${ }^{[14]}$. Between 1992-1994, 32 isolates of Tri. verrucosum from cases of T. corporis, T. faciei and T. capitis. Patients included dairy and cattle farmers, a slaughter man who worked in an abattoir, a veterinary tutor and children who lived on farms. Many patients lived in one of the three dairy farming areas of Victoria ${ }^{[15]}$. Zoonotic diseases are an ever-present concern in small animal veterinary practice and are often overlooked. These may cause human disease ranging from mild and self-limiting to fatal. The risk of development of a zoonotic disease can be lessened by early recognition of infected animals, proper animal handling, basic biosecurity precautions, and most importantly, personal hygiene ${ }^{[16]}$. Occupations at risk are farmers, slaughter men, Vets., laboratory and pet shop workers. Human infection occurs rarely by direct contact with infected soil ${ }^{[17]}$. It had been observed that the greatest economic and human health problems in the developed countries come from Dermatophytosis of domestic cattle. Approximately $60 \%$ of children were affected by T. capitis in some regions, and more than $50 \%$ of the population in some parts of Europe was reported to have T. pedis. $R W$ in humans is usually characterized by pruritus and inflammation that is most severe at the edges, with erythema, scaling and occasionally blister formation. Central clearing is sometimes seen, particularly in T. corporis resulting in the formation of a classic $R W$ lesion $^{[18]}$. Dermatophytes are able to penetrate the keratinized layer of skin, hair and nails. The commonest features are scaling and erythema of the skin. In hairy areas, alopecia can develop. Sometimes more inflammatory changes with boggy swelling occur, especially on the scalp and beard areas. T. pedis is a common infection in the general population. A large European population-based survey found evidence of fungal foot disease in $35 \%$ of patients ${ }^{[19]}$. Tri. verrucosum infects cattle, farm buildings and straw. Tri. mentagrophytes can be transmitted by cattle and domestic animals ${ }^{[20]}$. Dermatophytes spp. are the most common causative agents of Tinea in rural areas of Iran ${ }^{[21]}$. Zoonotic Dermatomycosis infection as T. pedis and manuum was found in $19.4 \%$ farmers. T. pedis and manuum was found in $14.3 \%$ forestry workers. One T. corporis was determined in the farmer group were found in the forestry group. The most frequently isolated agent in the two groups was Tri. rubrum. The frequencies of superficial mycosis were found to be higher in the farmer group than in the forestry group, although similar etiological agents were isolated in both groups. The farmers had greater rates of contact with zoonotic pathogenic fungi present in soil as well as from infected farm animals than the foresters ${ }^{[22]}$. Dermatophytes most common isolated from toenails and skin lesion where it is identified in about $60 \%$ of patients ${ }^{[23]}$. In favorable conditions untreated infection can spread to other glabrous skin regions like skin on calves or hands ${ }^{[24]}$. Cutaneous mycosis describes a wide spectrum of fungal infections caused by Dermatophytes spp. Zoophilic as Tri. verrucosum, is associated with wild and domestic animals ${ }^{[25]}$. Eight calves, raised in a farm in Erzurum province during winter season, were referred to the clinic with complaints of skin lesions of $R W$. Additionally, the owner had T. corporis of the arm with an erythematous, scurfy, crusty and pruritic lesion. The isolated agents were identified as Tri. verrucosum. The identical strain isolated was verified in both samples of calves and the owner ${ }^{[26]}$. Zoophilic Dermatophytosis is a major public and veterinary health problem globally widespread among cattle, during 2006-2007, Only 5.2\% cases of Dermatophytosis were identified in cattle and Tri. verrucosum was the exclusive fungus isolated from animals. Moreover, $20.8 \%$ cases of human Dermatophytosis were identified and Tri. verrucosum was the prevalent causative agent in the body, scalp, foot, nail and groin of the patients. Tri. verrucosum was the predominant cause of Dermatophytosis in livestock and dairy farmers. Occurrence of Dermatophytosis in humans and cattle and confirms that the Dermatozoonosis are responsible for predominant forms of the disease in people who were in contact with cattle $e^{[27]}$. Once the disease is introduced into a herd, it spreads rapidly among susceptible animals. Close confinement, age, breed of animal and production system coupled with prolonged wetting are believed to be important predisposing factors. In spite of the significance of $R W$ in global economy, the disease has not been adequately studied in Nigeria. Although some attempts have been made at documenting human Dermatophytosis ${ }^{[28]}$. Superficial mycosis is more prevalent in tropical and subtropical countries including India, Tri. spp., is proved most common causative agents. Such fungi attack various parts of the body and lead to Dermatophytosis as T. pedis (athlete's foot) effects on the feet; T. unguium on the fingernails and toenails; T. corporis on the arms, legs and trunk, T. cruris 
(jock itch) groin area ; T. manuum hands and palm area, T. capitis on the scalp, T. barbae affects facial hair, $T$. faciei on the face ${ }^{[29]}$.

The aim of this research project: The present study was aimed for obsevation occupational health hazards of farmers. It will provide firstly a description brief of camel farms at Taif area, morbidity rates of infected camels by superfacial skin mycosis in addation the zoonotic superfacial skin mycosis diseases affected farmers. Descripe sources of zoonotic dermatophyte, assessing the frequency of infections with zoophilic spp. among farmers compared to non-farmers. Explain the morbidity rates of zoonotic dermatophytosis and identification of fungal pathogenes. This are very imporatan of health care for farmers to recognize and prevent zoonotic diseases.

\section{Materials and methods}

Understudy field area: Taif area was the selected area for search project, it was started by the preparation of agreement paper from farm owners. Visits were done of the camel farms and explained the aim of search project for permit the examination on camels and farmers, this visits were ended by taken agreement papers of farm owners, steps of clinical examination and specimens collection. Camel farms are about $($ No. $=200 \pm 30)$ at Taif area according to collected information from owners and farmers. Camels in each farm were $($ No. $=50 \pm 20)$. Farm owners always occupy 1 farmer/30 camels. Nationality about farmers were mostly Sudanese, Somalis and others (Pakistanis, Bengalis).

Understudy groups preparation: It was carried on for the preparation of understudy and control groups from camels and farmers for serial clinical examination and record every data. The clinical examination results and complains of camels and farmers were recorded.

Collection of data: The data were included the farms, camels and farmers were collected from farm history. Total of understudy were $15 \mathrm{camel}$ farms, $1187 \mathrm{camels}$ and 45 farmers. The control of camels were $15 \mathrm{camels}$ in each stage, also 15 non-farmers in each stage.

Clinical examination and specimens collection: Clinically examined the camels and the farmers. Total specimens from both were collected and differentiated according the lesions area. The specimens were sent under aseptic condition to Micro. Lab. for carry up (macroscopical and microscopical) examination and microbial culturing for isolation and identification of fungal etiological agents.

Diagnosis pattern: Macroscopical and Microscopical examination: Gross examination may occasionally reveal evidence of fungi as well. Gram stain, different concentrations of $\mathrm{KOH}$, is the most commonly used methods for the direct examination of specimens. Fungal spores may be viewed directly on hair shafts, this technique identifies a fungal infection in about $40 \%-70 \%$ of the infections but cannot identify the species of Dermatophytes. Isolation and Identification of Dermatophytes: Specimens were cultured on Myco-biotic Agar (Merck, Germany) and Sabroud dextrose agar (SDA), (Merck, Germany) slant tubes, then incubated at $25-30^{\circ} \mathrm{C}$ for 4weeks. Isolates Dermatophytes and saprophytic fungi were identified based on morphology and microscopic features ${ }^{[30-32]}$. Data analysis: The data were recorded from the previous steps and entered into Microsoft Excel Sheet, then summarized and analyzed ${ }^{[33]}$.

III. Results and discussion

Table and diagram 1: Description of the camel farms were examined for search project

\begin{tabular}{|l|c|c|}
\hline \multicolumn{2}{|c|}{ Camel farms were examined } \\
\hline $\begin{array}{l}\text { Stages } \\
\text { Farms *No. }\end{array}$ & $\begin{array}{c}\text { Farmers *No. } \\
\text { (1 Farmer / 30 camels) }\end{array}$ \\
\hline Stage I & & 1 \\
\hline $\mathbf{1}$ & 30 & 2 \\
\hline $\mathbf{2}$ & 45 & 2 \\
\hline $\mathbf{3}$ & 63 & 3 \\
\hline $\mathbf{4}$ & 71 & 3 \\
\hline $\mathbf{5}$ & 80 & 4 \\
\hline $\mathbf{6}$ & 98 & 4 \\
\hline $\mathbf{7}$ & 102 & 19 \\
\hline Total *No. =7 & 489 & 5 \\
\hline Stage II & & 3 \\
\hline $\mathbf{8}$ & 122 & 2 \\
\hline $\mathbf{9}$ & 73 & 2 \\
\hline $\mathbf{1 0}$ & 52 & 3 \\
\hline $\mathbf{1 1}$ & 66 & 4 \\
\hline $\mathbf{1 2}$ & 85 & 3 \\
\hline $\mathbf{1 3}$ & 96 & 4 \\
\hline $\mathbf{1 4}$ & 89 & 26 \\
\hline $\mathbf{1 5}$ & 115 & \\
\hline Total *No. = 8 & 698 & \\
\hline Total Search Project & & \\
\hline
\end{tabular}




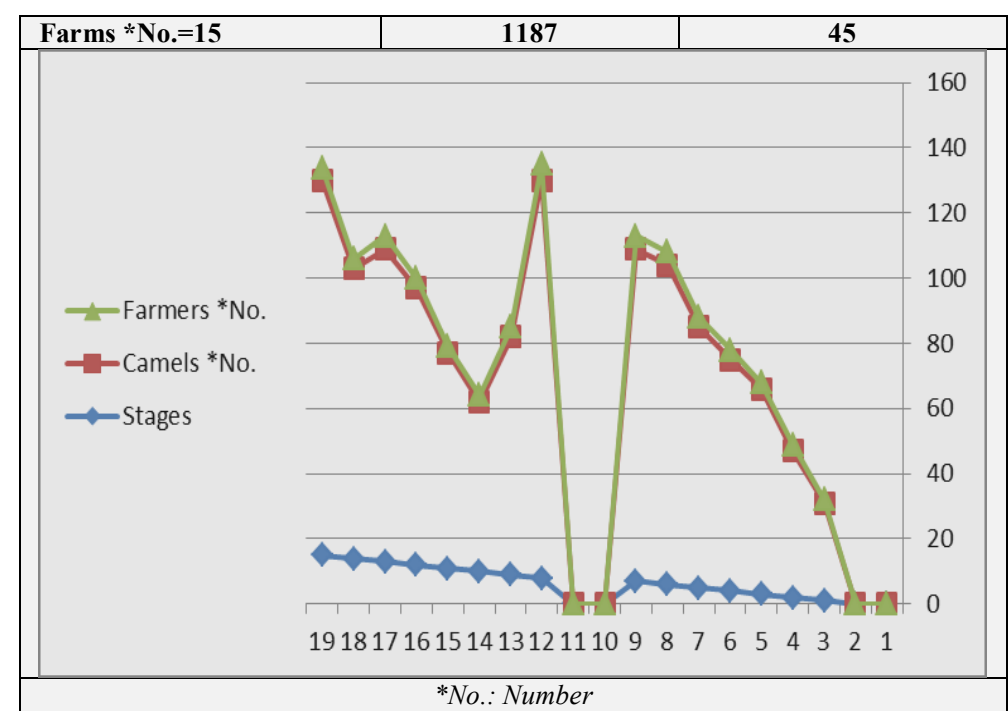

Table and diagram 1show description of the camel farms were examined for search project, the work were divided into 2 stages. Stage I contained 7 farms, 489 camels and 19 farmers, while stage II contained 8 farms, 698 camels and 26 farmers. Finally total farms were 15, camels 1187 and farmers 45 respectively.

Table and diagram 2: Incidence of the number and nationality for farmers

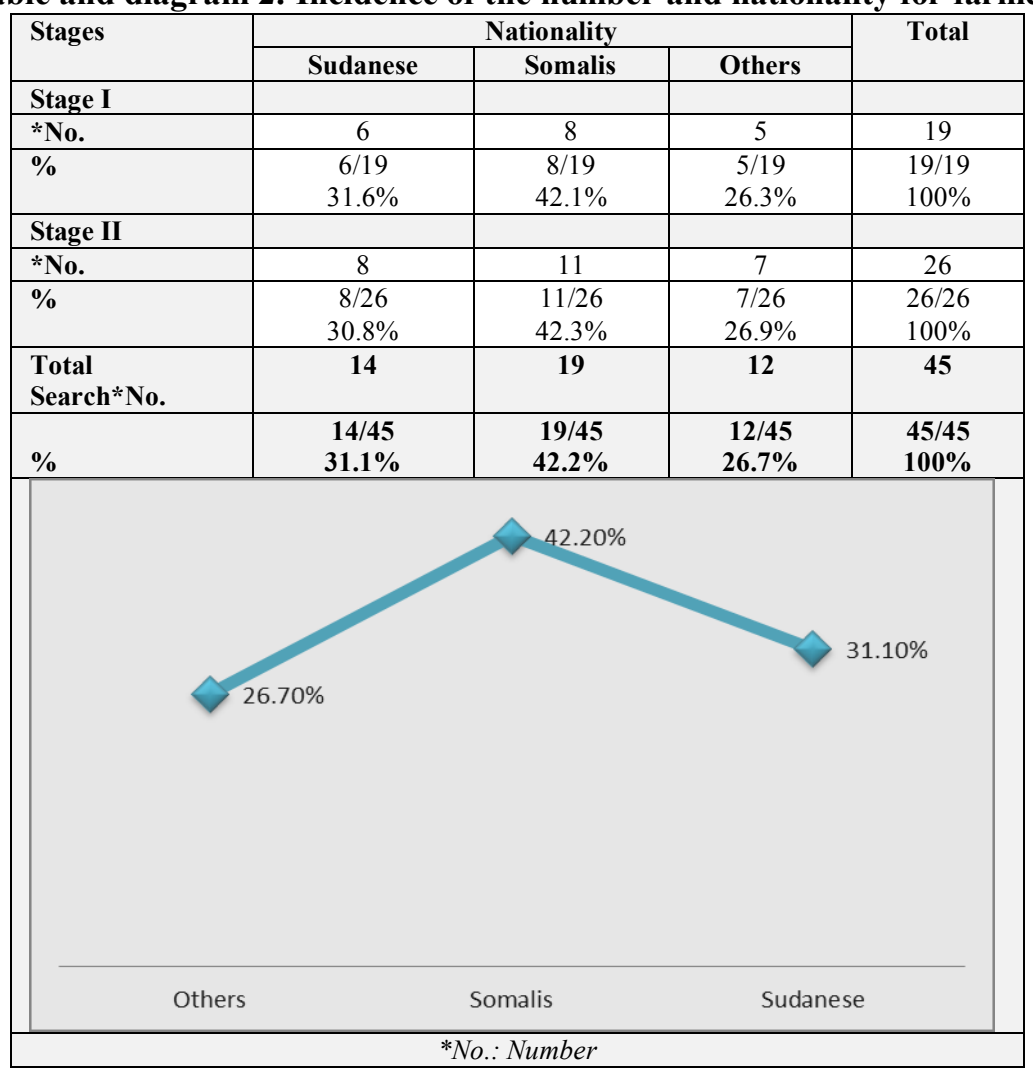

Table and diagram 2 show incidence of the number and nationality for farmers, in stage I were 19 farmers $42.1,31.6$ and $26.3 \%$, stage II were 26 farmers were $42.3,30.8$ and $26.6 \%$, finally total were 45 farmers as $42.2,31.1$ and $26.7 \%$ with nationality Somalis, Sudanese and others respectively. 
Search Project Report; Field Study on Farm Workers Occupational Health Hazards Associated ...

Table and diagram 3: Incidence of examined camels for superficial skin mycosis

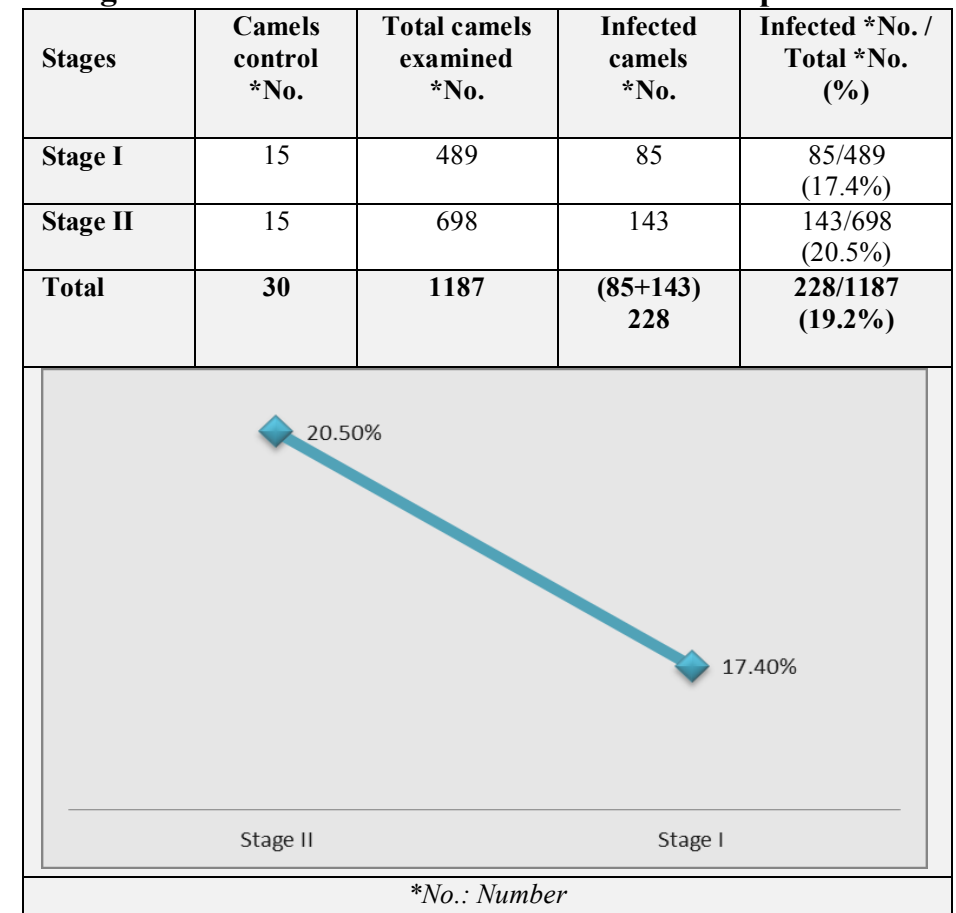

Table and diagram 3 show incidence of examined camels for superficial skin mycosis, stage I and II results were 17.4 and $20.5 \%$ while total result was $19.2 \%$ camels infected by superficial skin mycosis. Control camels were non infected. A survey of Ringworm $(R W)$ in camels showed over $25 \%$ of young animals suffered from Tri. verrucosum infection. within $11 \%{ }^{[4]}, 136$ examined, $56.6 \%$ Tri. verrucosum, were isolated. Both female and male camels were susceptible and camels less than 3yrs. old were more susceptible to infection ${ }^{[6]}$. Higher prevalence of $R W$ due to Tri. spp. infection in Bactrian than in Dromedary camel and a higher prevalence in the she camel $77 \%$ than males $23 \%$, which included Tri. verrucosum, and Tri. rubrum. which caused sporadic cases of skin infections in individually maintained camels as well as affecting many camels in the herds ${ }^{[7]}$. Persistent Dermatomycosis $(R W)$ caused by Tri. verrucosum affected 20dairy calves. Two animal attendants developed skin lesions ${ }^{[9]}$.

Table and diagram 4: Incidence of examined farmers for zoonotic superficial skin mycosis

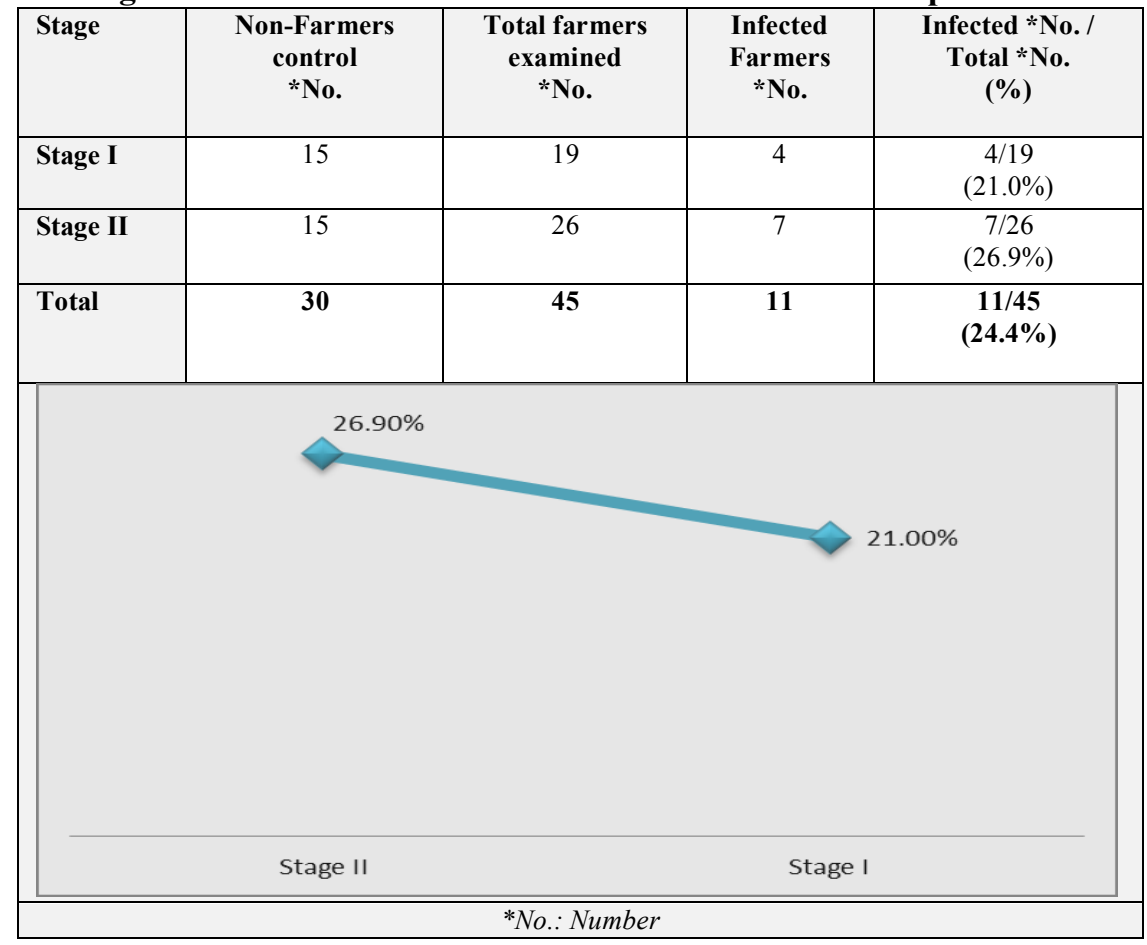


Table and diagram 4 show incidence of examined farmers for zoonotic superficial skin mycosis, stage I and II results were in 21.0 and $26.9 \%$, as well total result was $24.4 \%$ infected farmers by zoonotic superficial skin mycosis. Non-farmers control were non infected. Fungal infections of the skin are especially typical of farmers who spend several hours in rubber boots which provide an ideal microclimate for the development of fungal feet infections ${ }^{[10]}$. In 1997 skin diseases formed $10.8 \%$ of all newly acknowledged occupational diseases in farmers in Poland, while the respective figures for 1995 and 1996 were $11.2 \%$ and 13.4\%, in 1994 a total of 559 farmers with skin problems had been subjected to medical evaluation because of possible occupational dermatitis. In the same year, 37occupational skin diseases in farmers were acknowledged and compensated which comprised $12.9 \%$ of all occupational diseases in farmers ${ }^{[1]}$. There is no compulsory medical assessment before one starts work as a farmer. Many patients meet an occupational health professional for the first time when the disease is already advanced and legal action towards obtaining an occupational rent has already been issued. In these circumstances, confirming or rejecting the possible occupational etiology of a given dermatomes is very difficult ${ }^{[12]}$. The frequency of zoophilic fungal infections among farmers compared to non-farmers in eastern Poland, was carried out on adult patients with a suspicion of fungal infection of skin or its appendages. Dermatophytes infection was found in farmers 55.2\%. whereas zoophilic dermatophytes in farmers $4.3 \%$. Zoophilic fungi were responsible either for superficial mycosis ${ }^{[13]}$. Animals can infect humans with Dermatophytes. An occupational relationship is established when the same fungus is isolated from both the animal and worker, 995cases of zoophilic Dermatophytosis were registered as occupational dermatomes in the farmer German Democratic Republic over a 4yrs. period ${ }^{[14]}$. Between 1992-1994, 32isolates of Tri. verrucosum from cases of $T$. corporis, $T$. faciei and T. capitis. Patients included dairy and farmers, a slaughter man who worked in an abattoir, a veterinary tutor and children who lived on farms ${ }^{[15]}$. Zoonotic diseases are an everpresent concern in small animal veterinary practice and are often overlooked. These may cause human disease ranging from mild and self-limiting to fatal. The risk of development of a zoonotic disease can be lessened by early recognition of infected animals, proper animal handling, basic biosecurity precautions, and, most importantly, personal hygien ${ }^{[16]}$. Occupations at risk are farmers, slaughter men, Vets., laboratory and pet shop workers. Human infection occurs rarely by direct contact with infected soil ${ }^{[17]}$. It had been observed that the greatest economic and human health problems in the developed countries come from Dermatophytosis of domestic cattle. Approximately $60 \%$ of children and more than $50 \%$ of the population in some parts of Europe. A large European population-based survey found evidence of fungal foot disease in $35 \%$ of patients ${ }^{[19]}$. Dermatophytes infects cattle, farm buildings and straw can be transmitted by cattle and domestic animals ${ }^{[20]}$. Zoonotic Dermatomycosis infection was found in 19.4-14.3\% in farmers. The frequencies of superficial mycosis were found to be higher in the farmer than forestry group, although similar etiological agents were isolated in both groups. The farmers had greater rates of contact with zoonotic pathogenic fungi present in soil as well as from infected farm animals than the foresters ${ }^{[22]}$. It is the most common of all Dermatophytes that can be isolated from toenails and skin lesion where it is identified in about $60 \%$ of patients ${ }^{[23]}$. In favorable conditions untreated infection can spread to other glabrous skin regions like skin on calves or hands ${ }^{[24]}$. Cutaneous mycosis describes a wide spectrum of fungal infections caused by Dermatophytes spp. Zoophilic species of Dermatophytes, is associated with wild and domestic animals ${ }^{[25]}$. Eight calves, raised in a farm in Erzurum province during winter season, were referred to the clinic with complaints of skin lesions of $R W$. Additionally, the owner had Dermatophytes infection of the arm, identical strain isolated was verified in both samples of calves and the owner ${ }^{[26]}$. Zoophilic Dermatophytosis is a major public and veterinary health problem globally widespread among cattle, during 2006-2007, Only 5.2\% cases of Dermatophytosis were identified in cattle the exclusive fungus isolated from animals. Moreover, 20.8\% cases of human Dermatophytosis were identified was the prevalent causative agent for Dermatophytosis in the body, scalp, foot, nail and groin of the patients. It was the predominant cause of Dermatophytosis in livestock and dairy farmers. Occurrence of Dermatophytosis in humans and cattle and confirms that the Dermatozoonosis are responsible for predominant forms of the disease in people who were in contact with cattle ${ }^{[27]}$. Once the disease is introduced into a herd, it spreads rapidly among susceptible animals. Close confinement, age, breed of animal and production system coupled with prolonged wetting are believed to be important predisposing factors. In spite of the significance in global economy, the disease has not been adequately studied in Nigeria. Although some attempts have been made at documenting human Dermatophytosis ${ }^{[28]}$. Superficial mycosis is more prevalent in tropical and subtropical countries including India ${ }^{[29]}$. 
Search Project Report; Field Study on Farm Workers Occupational Health Hazards Associated ...

Table and diagram 5: Incidence of zoonotic superficial skin mycosis lesions area for farmers

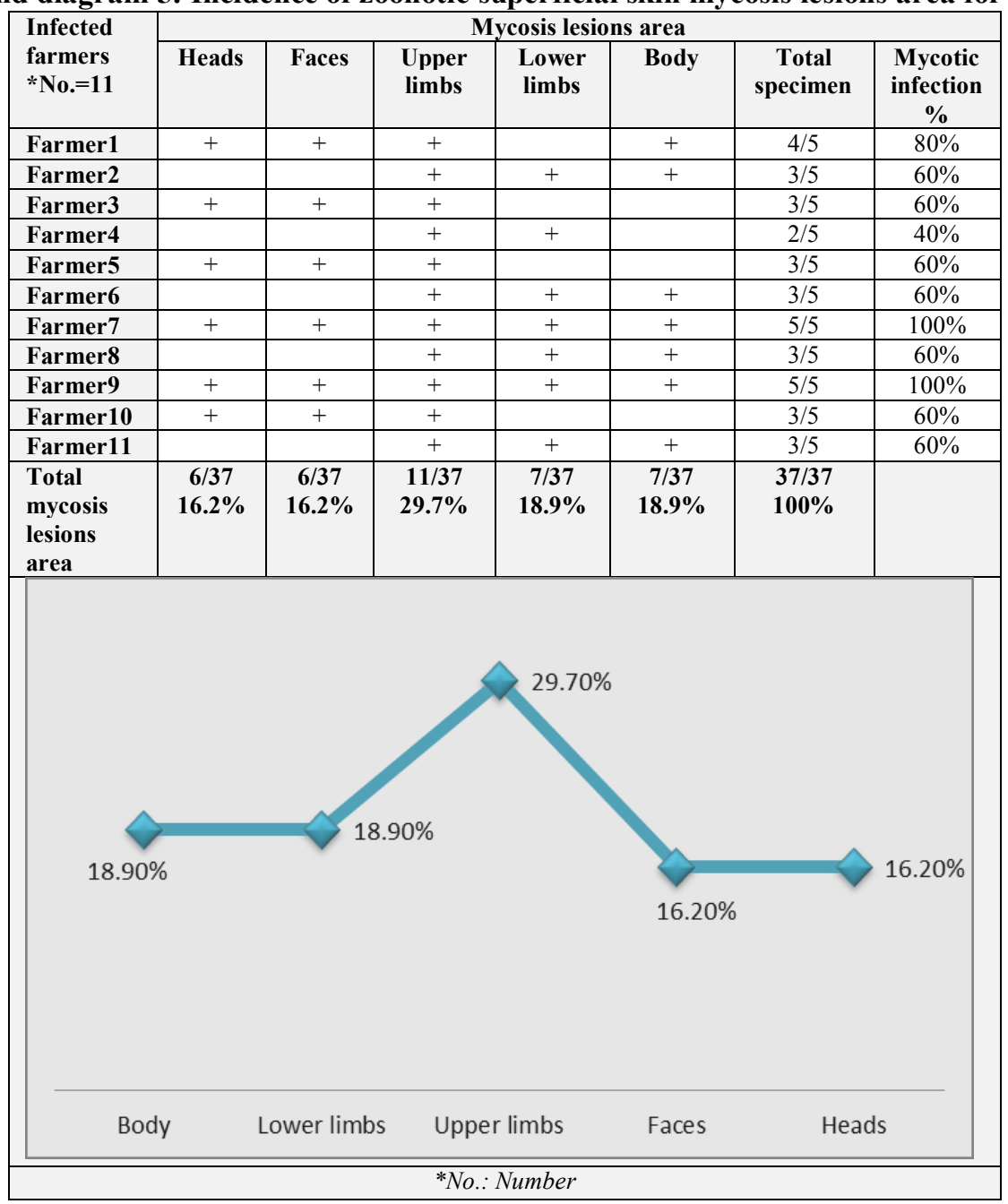

Table and diagram 5 show incidence of zoonotic superficial skin mycosis lesions area for farmers, the 11 farmers had given 37specimens from their lesions area. Specimens resulted in 29.7, 18.9, 18.9, 16.2 and $16.2 \%$ from upper limbs, lower limbs, body, heads and faces of infected farmers respectively. The more infected farmers were $7^{\text {th }}$ and $9^{\text {th }}$ farmers.

Table and figure 6: Incidence of Dermatophytes spp. from positive specimens of zoonotic superficial skin mycosis lesions for farmers

\begin{tabular}{|c|c|c|c|c|}
\hline $\begin{array}{l}\text { Dermatophytes *Spp. } \\
\text { Total *No.=37 }\end{array}$ & $\begin{array}{l}\text { *Spp. isolated } \\
\text { *No. }\end{array}$ & $\begin{array}{l}\text { *Spp. *No. / } \\
\text { Total *No. }\end{array}$ & $\begin{array}{c}\text { *Spp. isolated } \\
\%\end{array}$ & Total \\
\hline \multicolumn{5}{|l|}{ Heads $*$ No. $=6$} \\
\hline \multirow[t]{2}{*}{${ }^{*} T$. capitis } & 6 & $6 / 64$ & $9.4 \%$ & \\
\hline & & & & $6 / 64=9.4 \%$ \\
\hline \multicolumn{5}{|l|}{ Faces $*$ No. $=6$} \\
\hline \multirow{3}{*}{$\begin{array}{l}* T \text {. barbae } \\
{ }^{* T} \text {. faciei }\end{array}$} & 5 & $5 / 64$ & $7.8 \%$ & \\
\hline & 3 & $3 / 64$ & $4.7 \%$ & \\
\hline & & & & $8 / 64=12.5 \%$ \\
\hline \multicolumn{5}{|l|}{ Upper limbs *No. $=11$} \\
\hline \multirow{3}{*}{$\begin{array}{l}* T \text {. unguium } \\
* T \text {. manuum }\end{array}$} & 11 & $11 / 64$ & $17.2 \%$ & \\
\hline & 11 & $11 / 64$ & $17.2 \%$ & \\
\hline & & & & $22 / 64=34.4 \%$ \\
\hline \multicolumn{5}{|l|}{ Lower $\operatorname{limbs} *$ No. $=7$} \\
\hline \multirow{5}{*}{$\begin{array}{l}\text { *T. unguium } \\
\text { *T. pedis } \\
\text { *Tri. verrucosum } \\
\text { *Tri. rubrum }\end{array}$} & 7 & $7 / 64$ & $10.9 \%$ & \\
\hline & 7 & $7 / 64$ & $10.9 \%$ & \\
\hline & 2 & $2 / 64$ & $3.1 \%$ & \\
\hline & 1 & $1 / 64$ & $1.6 \%$ & \\
\hline & & & & $17 / 64=26.6 \%$ \\
\hline \multicolumn{5}{|l|}{ Body *N0.=7 } \\
\hline$* T$. corporis & 7 & $7 / 64$ & $10.9 \%$ & \\
\hline${ }^{* T}$. cruris & 2 & $2 / 64$ & $3.1 \%$ & \\
\hline
\end{tabular}


Search Project Report; Field Study on Farm Workers Occupational Health Hazards Associated ...

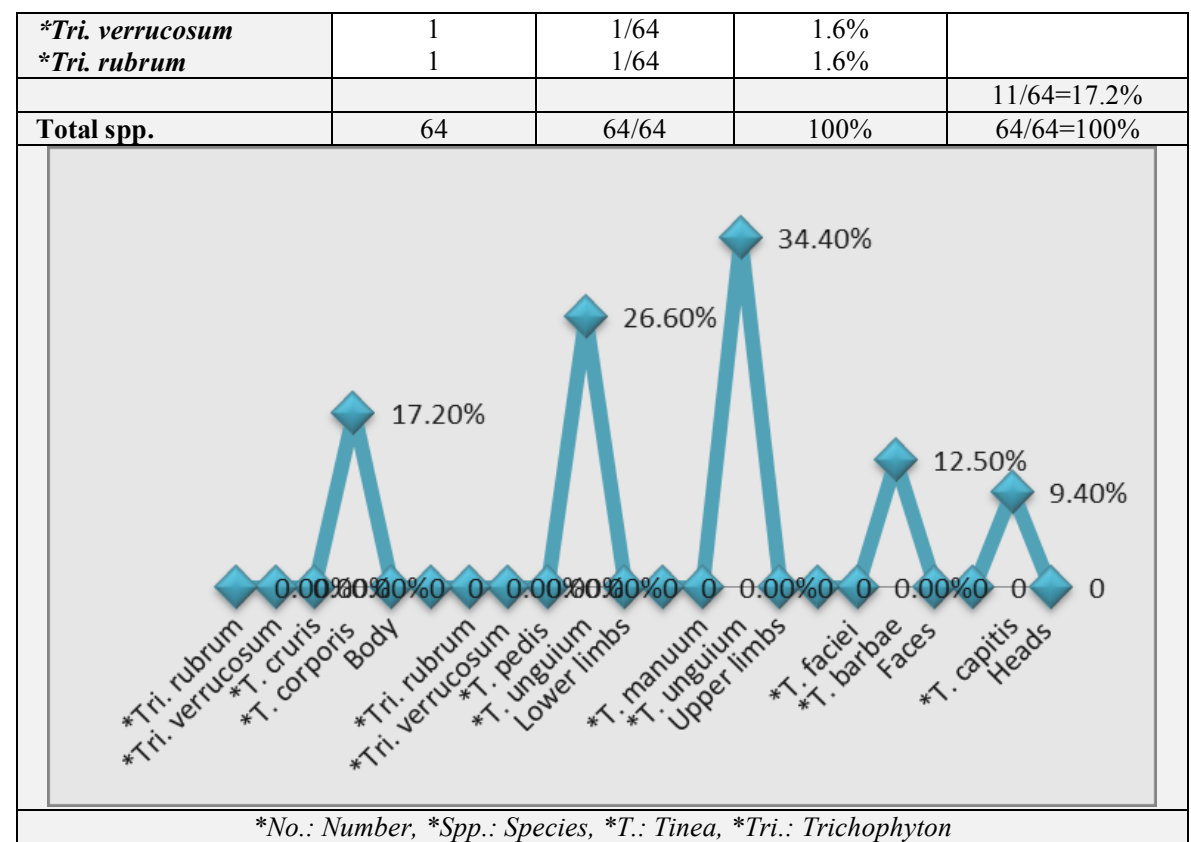

Table and figure 6 show incidence of Dermatophytes spp. from positive specimens of zoonotic superficial skin mycosis lesions for farmers, the results were in 34.4, 26.6, 17.2, 12.5 and $9.4 \%$ from upper limbs were included (T. unguium and T. manuum), lower limbs (T. unguium, T. pedis, Tri. verrucosum and Tri. rubrum), body (T. corporis, T. cruris, Tri. verrucosum and Tri. rubrum), faces (T. barbae and T. faciei) and heads ( $T$. capitis) respectively.

Table and figure 7: Incidence of the total Dermatophytes spp. from positive specimens of zoonotic superficial skin mycosis lesions for farmers

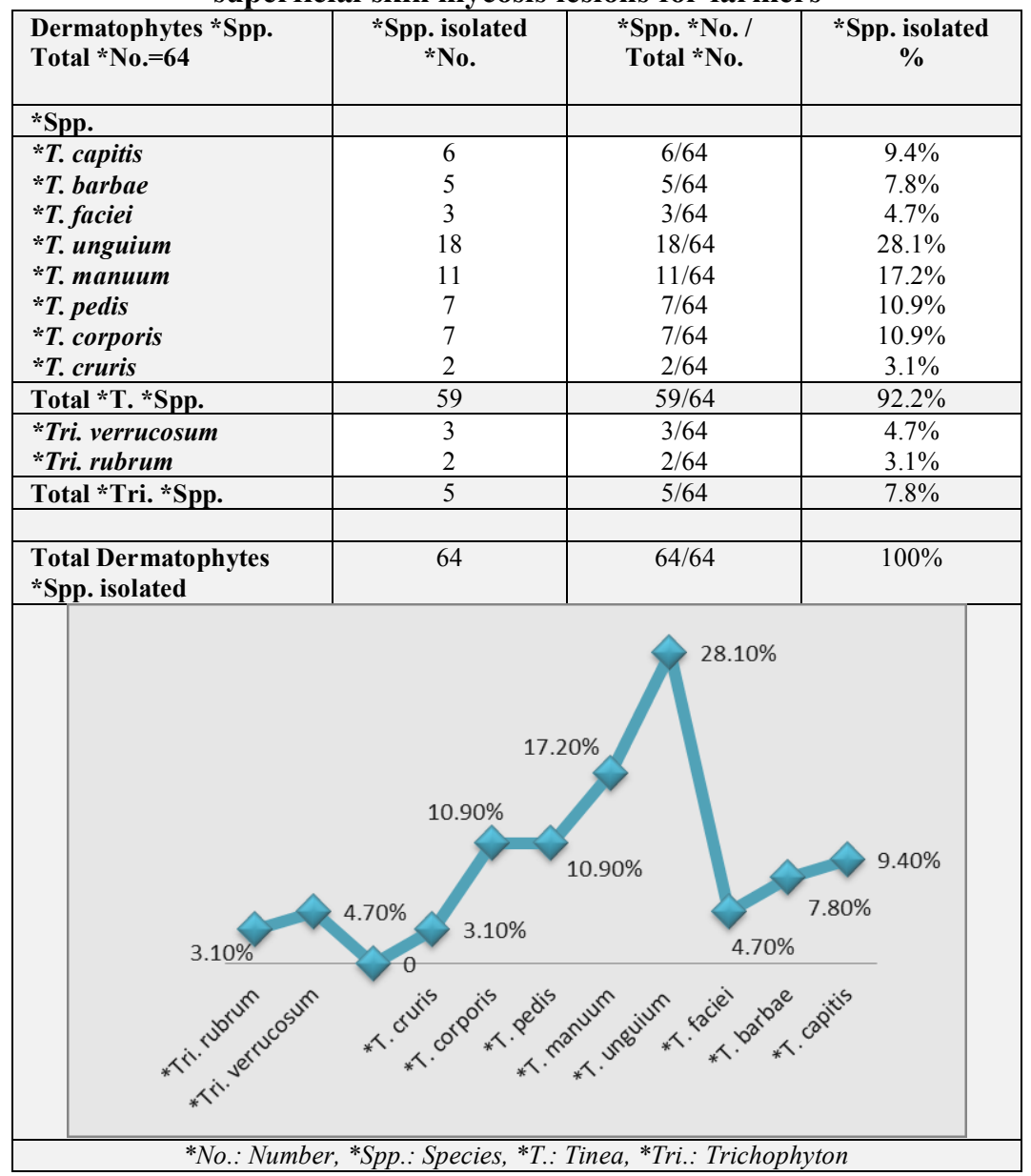


Table and figure 7 show incidence of the total Dermatophytes spp. from positive specimens of zoonotic superficial skin mycosis lesions for farmers, the results were 92.2 and $7.8 \%$ of $T$. and Tri. The results of Tinea were 28.1, 17.2, 10.9, 10.9, 9.4, 7.8, 4.7 and 3.1\% for T. unguium, T. manuum, T. pedis, T. corporis, T. capitis, T. barbae, and T. cruris. While Trichophyton were 4.7 and $3.1 \%$ for Tri verrucosum and Tri. rubrum respectively. The frequency of zoophilic fungal infections among farmers compared to non-farmers in eastern Poland, was carried out on adult patients with a suspicion of fungal infection of skin or its appendages. Dermatophytes infection Tri. verrucosum was found in 3 cases ${ }^{[13]}$. Between 1992-1994, 32 isolates of Tri. verrucosum from cases of T. corporis, T. faciei and T. capitis. Patients included dairy and cattle farmers, a slaughter man who worked in an abattoir, a veterinary tutor and children who lived on farms. Many patients lived in one of the three dairy farming areas of Victoria. A few lived in the outer suburbs of Melbourne. One cattle farmer came from south-east New South Wales ${ }^{[15]}$. Approximately $60 \%$ of children were affected by $T$. capitis in some regions, and more than $50 \%$ of the population in some parts of Europe was reported to have $T$. pedis. RW in humans is sometimes seen, particularly in T. corporis resulting in the formation of a classic RW lesion $^{[18]}$. T. pedis is a common infection in the general population ${ }^{[19]}$. Tri. verrucosum infects cattle, farm buildings and straw. Tri. mentagrophytes can be transmitted by cattle and domestic animals ${ }^{[20]}$. Dermatophytes spp. are the most common causative agents of Tinea in rural areas of Iran ${ }^{[21]}$. Zoonotic Dermatomycosis infection as T. pedis and manuum was found in 19.4\% farmers. T. pedis and manuum was found in $14.3 \%$ forestry workers. One T. corporis was determined in the farmer group were found in the forestry group. The most frequently isolated agent in the two groups was Tri. rubrum ${ }^{[22]}$. Cutaneous mycosis describes a wide spectrum of fungal infections caused by dermatophytes spp. Zoophilic species of Dermatophytes, as Tri. verrucosum, is associated with wild and domestic animals ${ }^{[25]}$. Eight calves, raised in a farm in Erzurum province during winter season, were referred to the clinic with complaints of skin lesions of RW. Additionally, the owner had T. corporis of the arm with an erythematous, scurfy, crusty and pruritic lesion. The isolated agents were identified as Tri. verrucosum. The identical strain isolated was verified in both samples of calves and the owner $^{[26]}$. Zoophilic Dermatophytosis is a major public and veterinary health problem globally widespread among cattle, during 2006-2007, Only 5.2\% cases of Dermatophytosis were identified in cattle and Tri. verrucosum was the exclusive fungus isolated from animals. Moreover, 20.8\% cases of human dermatophytosis were identified and Tri. verrucosum was the prevalent causative agent for Dermatophytosis in the body, scalp, foot, nail and groin of the patients. Tri. verrucosum was the predominant cause of dermatophytosis in livestock and dairy farmers. Occurrence of Dermatophytosis in humans and cattle and confirms that the dermatozoonosis are responsible for predominant forms of the disease in people who were in contact with cattle ${ }^{[27]}$. Once the disease is introduced into a herd, it spreads rapidly among susceptible animals. Close confinement, age, breed of animal and production system coupled with prolonged wetting are believed to be important predisposing factors. In spite of the significance of RW in global economy, the disease has not been adequately studied in Nigeria. Although some attempts have been made at documenting human Dermatophytosis ${ }^{[28]}$. Superficial mycosis is more prevalent in tropical and subtropical countries including India, Tri. spp., is proved most common causative agents. Such fungi attack various parts of the body and lead to Dermatophytosis as T. pedis (athlete's foot) effects on the feet; T. unguium on the fingernails and toenails; T. corporis on the arms, legs and trunk, T. cruris (jock itch) groin area ; T. manuum hands and palm area, T. capitis on the scalp, T. barbae affects facial hair, $T$. faciei on the face ${ }^{[29]}$.

\section{Conclusion}

It's important to note that there is high level of zoophilic Dermatophytosis are sporadic infections of farmers caused by Dermatophytes spp., typically invading animals. There is no compulsory medical assessment before one starts work as a farmer. Many patients meet an occupational health professional for the first time when the disease is already advanced and legal action towards obtaining an occupational rent has already been issued. In these circumstances, confirming or rejecting the possible occupational etiology of a given dermatitis is very difficult. The frequency of zoophilic fungal infections among farmers higher compared to non-farmers. There is an occupational relationship is established when the same fungus is isolated from both the animal and worker. Many improvements are needed in the field of occupational medicine in farming

\section{Acknowledgment}

Thankful was directed to camel farm owners, farmers and laboratory technicians for their helps in producing this result paper of search project. 


\section{References}

[1]. Midgley, G., Clayton, Y. and Hay, R., 1997. Medical Mycology. Mosby-Wolfe, Chicago.

[2]. Jabłońska, S. and Chorzelski, T., 2002. Choroby skóry. PZWL, Warszawa, 72-73.

[3]. Adamski, Z. and Batura-Gabryel, H., 2005. Mikologia lekarska dla lekarzy i studentów. Wyd. Naukowe AM im. K. Marcinkowskiego w Poznaniu, PP: 19-20, 30-45, 47-48.

[4]. Kuttin, S., Alhanaty, E., Feldman, M., Chaimovits, M. and Müller, J., 1989. Dermatophytosis of camels, Med. Myco., 24:341-344.

[5]. Agab, H., 1993. Epidemiology of camel diseases in eastern Sudan with emphasis on brucellosis, M. V. Sci. Thesis Uni. Khartoum. Khartoum, Sudan.

[6]. Wisal, G., Abdalla, G. and Salim, M., 2010. Isolation and identification of Dermatophytes from infected Camels. Sudan J. Vet Res., 25:49-53.

[7]. Tuteja, F., Patil, N., Narnaware, S., Nagarajan, G. and Dahiya, S., 2013. Camel dermal mycoses caused by dermatophytes, J. Camel Practice and Res., 20:157-165.

[8]. Schuman, S., 1990. Practice-based agromedicine: the need for clientcentered research. Am. J. Ind. Med., 18:405-408.

[9]. Wabacha, J., Gitau, G., Bebora, L., Bwanga, C., Wamuri, Z. and Mbithi, P., 1998. Occurrence of dermatomycosis (ringworm) due to Trichophyton verrucosum in dairy calves and its spread to animal attendants : case report. J. South African Vet. Ass., 69:172-173.

[10]. Djyuvnl, L., Fkurqd, D. and Sudfxm, Z., 1994. Ergonomia i Higiena Pracy w Rolnictwie, PP: 49 - 52. Institute of Agricultural Medicine, Lublin.

[11]. Susitaival, P., Husman, L., Hollmen, A. and Horsmanheimo, M., 1995. Dermatoses determined in a population of farmers in a questionnairebased clinical study including methodology validation. Scand. J. Work Envoi. H., 21:30-35.

[12]. Radostaw, S., 1999. Occupational dermatitis in farmers: A proposal for diagnostic procedure. Ann. Agric. Envoi.. Med., 6:63-72.

[13]. Radostaw, S. and Wiestawa, S., 2000. Zoophilic and geophilic dermatophytosis among farmers and non-farmers in Eastern Poland. Ann. Agric. Envoi. Med., 7:125-139.

[14]. Seebacher, C., 2000. Epidemiology, clinic and treatment of dermatomycosis caused by zoophilic dermatophytes. Mycoses 43(Suppl. 1):4-7. German.

[15]. Mary, M., 2000. Human cases of cattle ringworm due to Trichophyton verrucosum in Victoria, Australia. Aust. J. Derma., 41:9094.

[16]. Weesw, J., Peregrine, A. and Armstrong, J., 2002. Occupational health and safety in small animal veterinary practice: Part I_ Nonparasitic zoonotic diseases. The Can. Vet. J., 43:631-636.

[17]. Fernandez-Torres, B., Mayayo, E., Boronat, J. and Guarro, J., 2002. Subcutaneous infection by Microsporum gypseum. Br. J. Derma., 146:311-313.

[18]. Acha, P. and Szyfres, B., 2003. Zoonosis and communicable diseases common to man and animals. Volume 1. Bacterioses and mycoses, 3rd ed., Pan American Health Organization (PAHO), Scientific and Technical Publication No. 580. Dermato-phytosis, Washington, DC., PP:332-339.

[19]. Burzykowski, T., Molenberghs, G. and Abeck, D., 2003. High prevalence of foot diseases in Europe: results of the Achilles Project. Mycoses, 46:496-505.

[20]. Khosravi, A. and Mahmoudi, M., 2003. Dermatophytes isolated from domestic animals in Iran. Mycoses, 46:222-225.

[21]. Rastegar, L., Akhlaghi, L., Falahati, M. and Alaghehbandan, R., 2005. Characteristics of dermatophytosis among children in an area south of Tehran, Iran. Mycoses, 48:32-37.

[22]. Idris, S., Demet, K., Ali, P., Sukru, O. and Mustafa, B., 2005. Dermatophytosis in forestry workers and farmers. Mycoses, 48:260264.

[23]. Das, S., Goyal, R. and Bhattacharya, S., 2007. Laboratory-based epidemiological study of superficial fungal infections. J. Derma., 34:248-253.

[24]. Nenoff, P., Mugge, C., Herrmann, J. and Keller, U., 2007. Tinea faciei incognito due to Trichophyton rubrum as a result of autoinoculation from onychomycosis. Mycoses, 50:20-25.

[25]. Mahmoudabadi, A., Yaghoobi, R. and Sadeghi, B., 2007. A large outbreak of Tinea capitis in a primary school. J. Infect., 54:e247e248.

[26]. Yunusmre, O., Mustafa, A. and Ekrem, K., 2009. Mycozoonosis associated with ringworm of calves in Erzurum province, Turkey. Kafkas Univ. Vet. Fak. Derg., 15:141-144.

[27]. Mohammad, R. and Seyed, G., 2011. Dermatophytes as a cause of epizoonosis in dairy cattle and humans in Iran: epidemiological and clinical aspects. Mycoses, 54:e52-e56.

[28]. Ndako, J., Osemwegie, O., Spencer, T., Olopade, B., Yunusa, G. and Banda, J., 2012. Ringworm as infection dermatophytes. Global Advanced Res. J. Med. and Med. Sci.,1:49-56.

[29]. Chowdhry, P., Gupta, S. and Nidhi, A., 2013. Diversity of fungi as human pathogen. Recent Res. In Sci. and Tec., 5:17-20.

[30]. Revankar, S. and Sutton, D., 2010. Melanized fungi in human disease. Cline. Micro. Rev., 23:884-928.

[31]. CDC., 2009. Biosafety in microbiological and biomedical laboratories, 5th ed. Centers for Disease Control and Prevention, Atlanta, GA .

[32]. Sutton, D., 2008. Basic mycology, In Hospenthal DR, Rinaldi MG (ed), Diagnosis and treatment of human mycoses. Humana Press, Towata, NJ., PP.:15-35.

[33]. Coulombier, D., Fagan, R., Hathcock, L. and Smith, C., 2001. Epi. Info. 6 Version 6.04.A Word Processing, Database and Statistical Program for Public Health. Centers for Disease Control and Prevention, Atlanta, Delaware, USA. 